\title{
Enhancement of polysaccharides accumulation in Dendrobium officinale by exogenously applied methyl jasmonate
}

\author{
Z.Q. YUAN, J.Y. ZHANG*, and T. LIU \\ School of Life Sciences, Shandong University of Technology, Zibo, Shandong, 255049, P.R. China
}

\begin{abstract}
The accumulation of polysaccharides, activities of sucrose metabolism enzymes, and the expression of sucrose biosynthetic genes in Dendrobium officinale were significantly affected by exogenous methyl jasmonate (MeJA). Application of MeJA increased the content of polysaccharides and the highest polysaccharide production occurred in the samples treated with $200 \mu \mathrm{M}$ MeJa. The MeJA application influenced polysaccharide biosynthesis rather than degradation because the activities of sucrose metabolism enzymes and the expressions of sucrose biosynthetic genes were upregulated by MeJA. Interestingly, low MeJA concentrations promoted accumulation of Dendrobium polysaccharides, while high MeJA amounts played an inhibitory role. The content of major constituent of polysaccharides, glucose and mannose, also increased after MeJa treatment.
\end{abstract}

Additional key words: gene expression, glucose, mannose, sucrose phosphate synthase, sucrose synthase.

\section{Introduction}

Dendrobium officinale, which belongs to the Orchidaceae family, is used in Chinese traditional medicine. The polysaccharides and alkaloids are main bioactive substances in D. officinale (Liu et al. 2005, Zhao et al. 2007), therefore, it is crucial to investigate regulatory mechanisms of their biosynthesis and possibility of its genetic manipulation (Yuan et al. 2014).

As an important endogenous signal molecule, methyl jasmonate (MeJA) is a major component in signal transduction pathways leading to biosynthesis of particular compounds under abiotic stresses, and it is also essential for the development of systemic acquired resistance under biotic stresses (Browse 2009). In the recent years, application of MeJA at non-toxic concentrations has been shown to be effective in the regulation of number of processes, such as plant growth (Pauwels et al. 2008), defence against oxidative stress (Schenk et al. 2000, Sasaki-Sekimoto et al. 2005), senescence and cell wall modification (Browse and Howe 2008), chlorophyll metabolism and photosynthesis
(Reymond et al. 2004, Jung et al. 2007). In addition, MeJA has been involved in inducing the formation of secondary metabolites, such as alkaloids and terpenoids (Okudera 2009, Vázquez-Flota et al. 2009).

Dendrobium polysaccharides can be hydrolyzed into monosaccharides glucose, mannose, xylose, and arabinose. These monosaccharides are produced by sucrose hydrolysis and derivatization. Sucrose phosphate synthase (SPS) is the key enzyme involved in the conversion of starch to sucrose in photosynthetic organs. SPS activity reflects the capacity of sucrose biosynthesis (Salvucci 1990). Sucrose accumulation in plants is due to the increase of SPS activity and decrease of invertase activity (Lingle 1999). However, the functions of sucrose synthase (SS) include degradation of sucrose, providing precursors for polysaccharide syntheses and regulating the assignment of sucrose into various metabolic pathways (Vaughn 2002). SPS and SS gene expressions are closely related with the accumulation of polysaccharides. Previous studies on polysaccharides

Submitted 18 November 2015, last revision 15 October 2016, accepted 17 October 2016.

Abbreviations: EDTA - ethylene diamine tetraacetic acid; HPLC - high performance liquid chromatography; MeJA - methyl jasmonate; MOPS - 3-(morpholino) propanesulfonic acid; MS - Murashige and Skoog; PDAD - photodiode array detector; PMP 3-methyl-1-phenyl-2-pyrazolin-5-one; SPS - sucrose phosphate synthase; SS - sucrose synthase; UDPG - uridine diphosphate glucose. Acknowledgements: The research was supported by the National Natural Science Foundation of China (Nos. 31100377 and 41201518) and the Project of Shandong Province Higher Educational Science and Technology Program (No. J16LE02).

* Corresponding author; e-mail: zhangjy1977@126.com 
have focused mainly on the extraction and pharmacological analysis, while few studies have investigated their accumulation and biosynthesis. Herein, $D$. officinale seedlings were used to investigate the regulatory effects of exogenous methyl jasmonate on polysaccharide biosyntheses, enzyme activities, and the

\section{Materials and methods}

Plants and methyl jasmonate treatments: The capsules of Dendrobium officinale Kimura et Migo were procured from the Yandang Mountains, ZheJiang province, China. Healthy seeds of uniform size were selected and surface was sterilized with $5 \%(\mathrm{~m} / \mathrm{v})$ solution of $\mathrm{NaClO}$ for $10 \mathrm{~min}$ followed by repeated washing with distilled water in ultra clean cabinet. Sterilized seeds were sown into culture flasks containing Murashige and Skoog (MS) basal medium with $30 \mathrm{~g} \mathrm{dm}^{-3}$ sucrose. After precultivation for 2 months, uniform size seedlings with completely expanded cotyledons were selected and transplanted into glass containers containing MS medium (60 seedlings per container). The experiment was carried out under a photosynthetic photon flux density of $100 \mu \mathrm{mol} \mathrm{m} \mathrm{s}^{-2}$, a 12-h photoperiod, day/night temperatures of $25 / 25^{\circ} \mathrm{C}$, and a relative humidity of $65-67 \%$. After $60 \mathrm{~d}$ of culture, seedlings with the height of $3-5 \mathrm{~cm}$ were transferred to new glass containers with 30 seedlings per container containing MS medium supplemented with MeJa at final concentrations 0 (control), 50, 100, 200, 500, and $1000 \mu \mathrm{M}$. Each treatment had three replicates. Every $6 \mathrm{~d}$, samples $(5 \mathrm{~g})$ of fresh seedlings from every treatment were stored in $-70{ }^{\circ} \mathrm{C}$ for further use.

Polysaccharide extraction was performed according to Zhang (2011) with some modifications. The seedlings were ground to a powder after being dried in an oven $\left(60^{\circ} \mathrm{C}, 3 \mathrm{~d}\right)$. The crushed powder (40 meshes) was extracted with petroleum ether at $70{ }^{\circ} \mathrm{C}$ for $1 \mathrm{~h}$ thrice and filtered. The residue was hydrolyzed with $0.5 \%(\mathrm{~m} / \mathrm{v})$ cellulase solution at $50{ }^{\circ} \mathrm{C}$ for $2 \mathrm{~h}$, and then further extracted with $90 \%(\mathrm{v} / \mathrm{v})$ ethanol at $90{ }^{\circ} \mathrm{C}$ for $0.5 \mathrm{~h}$. After each extraction, the solutions were separated from residues through filtration, and then extracted with double-distilled water at $25{ }^{\circ} \mathrm{C}$ for $2 \mathrm{~h}$ thrice. After concentrated using a rotary evaporator at $55{ }^{\circ} \mathrm{C}$, the polysaccharide extracts were precipitated by adding 5 -fold volume of ethanol at $4{ }^{\circ} \mathrm{C}$ for $24 \mathrm{~h}$, followed by centrifugation at $1500 \mathrm{~g}$ for $20 \mathrm{~min}$. The precipitate was lyophilized to yield the crude extract. The polysaccharides was washed successively with ethyl acetate and acetone, and then dissolved in water, and then lyophilized to yield the purified polysaccharides.

The polysaccharide content was determined by the phenol-sulfuric acid method (Dubois et al. 1956). The expression of sucrose biosynthesis related genes. The results will provide a theoretical basis for efficient synthesis of polysaccharides in $D$. officinale as well as a further understanding of the regulatory mechanisms of plant secondary metabolism.

colour reaction was initiated by mixing $2 \mathrm{~cm}^{3}$ of polysaccharide solution with $1 \mathrm{~cm}^{3}$ of a $10 \%(\mathrm{~m} / \mathrm{v})$ phenol solution and $5 \mathrm{~cm}^{3}$ of concentrated sulfuric acid. The reaction mixture was incubated in a boiling water bath for $15 \mathrm{~min}$. After cooling to the room temperature, the absorbance (A) of the mixture was determined at $490 \mathrm{~nm}$, and the total sugar content was calculated using D-glucose as a standard.

Determination of enzymes: Fresh samples of leaves were ground until obtaining a fine powder in the presence of liquid $\mathrm{N}_{2}$, ice-cold $100 \mathrm{mM} \mathrm{K}$-phosphate buffer (pH 7.0) containing $1 \mathrm{mM}$ EDTA, and $1 \mathrm{mM}$ phenyl methyl sulphonyl fluoride. After centrifugation at $14000 \mathrm{~g}$ for $30 \mathrm{~min}$, supernatant was collected and used as enzyme extract. The protein amount in the extract was determined by Bradford's method.

The activity of sucrose phosphate synthase (SPS) was assayed by the method of Lowell et al. (1989) with some modifications. SPS activity was measured by addition of $50 \mathrm{~cm}^{3}$ of dialysed enzyme preparation to $50 \mathrm{~cm}^{3}$ of a reaction mixture containing $100 \mathrm{mM}$ 3-(morpholino) propanesulfonic acid (MOPS)- $\mathrm{NaOH}(\mathrm{pH} 7.5), 20 \mathrm{mM}$ glucose-6-phosphate, $4 \mathrm{mM}$ fructose-6-phosphate, $3 \mathrm{mM}$ uridine diphosphate glucose (UDPG), $5 \mathrm{mM} \mathrm{MgCl}_{2}$, and $1 \mathrm{mM}$ EDTA (reaction without UDPG served as a negative control).

The activity of sucrose synthase (SS) in sucrose synthesis direction was assayed by the method of Hubbard et al. (1989) with some modifications. Enzyme assay comprised of $50 \mathrm{~cm}^{3}$ of dialyzed enzyme preparation and $50 \mathrm{~cm}^{3}$ of a reaction mixture containing $50 \mathrm{mM}$ MOPS-NaOH (pH 7.5), $15 \mathrm{mM} \mathrm{MgCl}_{2}, 25 \mathrm{mM}$ fructose and $25 \mathrm{mM}$ UDPG (reaction without UDPG served as a negative control).

Both the above mentioned reaction mixtures were incubated at $37^{\circ} \mathrm{C}$ in a circulating water bath $(60 \mathrm{~min}$ for SPS assay and $30 \mathrm{~min}$ for SS assay). The reactions were stopped by boiling in hot water bath for $3 \mathrm{~min}$ and allowed to cool to room temperature. Aliquots of $70 \mathrm{~cm}^{3}$ of the reaction mixture were reacted with equal volume of $30 \%(\mathrm{~m} / \mathrm{v}) \mathrm{KOH}$ and boiled for $10 \mathrm{~min}$ and finally allowed to cool to room temperature. To this, $1 \mathrm{~cm}^{3}$ of freshly prepared anthrone reagent (containing $76 \mathrm{~cm}^{3}$ of $\mathrm{H}_{2} \mathrm{SO}_{4}, 30 \mathrm{~cm}^{3}$ of distilled water and $150 \mathrm{mg}$ of anthrone) was added and the reactions were further incubated at 
$37^{\circ} \mathrm{C}$ for 20 min. Absorbance $\left(\mathrm{A}_{650}\right)$ was measured immediately in a microtiter plate using a plate reader (Varioskan Flash, Thermo Fisher Scientific, Waltham, USA). The amount of produced sucrose was used to estimate the enzyme activity.

Hydrolysis of polysaccharides and derivatization of monosaccharides: The standard reference substance glucosamine hydrochloride, D-glucose, and D-mannose were dissolved in double-distilled water, and concentrations were $12 \mathrm{mg} \mathrm{cm}^{-3}, 0.1 \mathrm{mg} \mathrm{cm}^{-3}$, and $0.1 \mathrm{mg} \mathrm{cm}^{-3}$, respectively. Polysaccharides of samples were dissolved in $10 \mathrm{~cm}^{3}$ of double-distilled water and were treated with $5 \mathrm{~cm}^{3}$ of $3.0 \mathrm{M} \mathrm{HCl}$ at $110{ }^{\circ} \mathrm{C}$ for $1 \mathrm{~h}$. Samples were cooled to room temperature and $\mathrm{pH}$ was adjusted to 7.0 with $3.0 \mathrm{M} \mathrm{NaOH}$.

According to Goubet et al. (2002), derivatization was carried out in tubes containing standards and polysaccharides. The hydrolyzed polysaccharide samples $\left(0.4 \mathrm{~cm}^{3}\right)$ were placed in the $2.0-\mathrm{cm}^{3}$ centrifuge tubes, and then $0.4 \mathrm{~cm}^{3}$ of $0.5 \mathrm{M}$ methanol solution of 3-methyl1-phenyl-2-pyrazolin-5-one (PMP) and $0.4 \mathrm{~cm}^{3}$ of $0.3 \mathrm{M}$ $\mathrm{NaOH}$ were added to each. The mixture was allowed to react in a water bath at $70{ }^{\circ} \mathrm{C}$ for $100 \mathrm{~min}$, then cooled to room temperature, and neutralized with $0.2 \mathrm{~cm}^{3}$ of $0.3 \mathrm{M}$ $\mathrm{HCl}$. The resulting solution was separated by liquidliquid extraction using a chloroform (three times, $2 \mathrm{~cm}^{3}$ ). After being shaken vigorously and centrifuged, the organic phase was carefully discarded to remove the excess reagents. Then, the aqueous layer was analyzed by high performance liquid chromatography (HPLC).

The analyses were performed with Waters HPLC system 600 (Milford, MA, USA) equipped with photodiode array detector (PDAD) operating at $250 \mathrm{~nm}$. The standard or supernatant was filtered and a $0.02 \mathrm{~cm}^{3}$ aliquot was injected onto the HPLC. Separations were carried out with symmetry column C18 $(250 \times 4.6 \mathrm{~mm}$, $5 \mu \mathrm{m}$ particle) and isocratic elution with a mobile phase of $20 \mu \mathrm{M}$ ammonium acetate and acetonitrile in a ratio of 90:10 (v/v). The gradient elution mode separation was programmed, $0-20 \mathrm{~min}(\mathrm{~B}: 17+17 \%), 20-30 \mathrm{~min}$

\section{Results and discussion}

The polysaccharides were obtained from the seedlings of $D$. officinale by the method of water-extraction and ethanol-precipitation. The cellulase method was mild and effective in breaking cell wall, promoting the polysaccharide solubility and improving the yield. Purified polysaccharides were detected by the phenolsulfuric acid method. Addition of MeJA significantly increased the content of polysaccharides in a concentration-dependent manner (Fig. 1). The maximum content of polysaccharides was obtained by adding $200 \mu \mathrm{M}$ MeJA. Nevertheless, when the concentration of
(B: $17+37 \%$ ) with a column temperature of $30{ }^{\circ} \mathrm{C}$ and detection wavelength of $250 \mathrm{~nm}$. The flow rate was set at $1.0 \mathrm{~cm}^{3} \mathrm{~min}^{-1}$. The glucose and mannose content of polysaccharides were quantified by a calibration curve with glucosamine hydrochloride as internal standard.

Gene expression analysis: Real-time quantitative PCR was used to monitor the expressions of the SPS and SS genes at different times after treatments by different MeJA concentrations. Total RNA was extracted from leaves with the RNA prep pure kit (Tiangen, Beijing, China) and cDNAs used for PCR were synthesized with cDNA synthesis kit (Fermentas, Pittsburgh, USA). The $18 S$ rRNA gene was used as the internal reference gene. The PCR primers used were as follows: SPS forward, 5'-GTCTTGAAAGGGAACGAG-3', SPS reverse, 5'-GATAACATTTAGCCTGGTG-3', SS forward, 5'-GACATCGTCTTGAAAGGGAA-3', SS reverse, 5'-CACCACTTTCTCCCACGA-3', 18S rRNA forward, 5'-CCAGGTCCAGACATAGTAAG-3', and 18S rRNA reverse, 5'-GTACAAAGGGCAGGGACGTA-3'. For each primer/cDNA sample combination, PCRs were performed six-times. Relative quantitative real-time PCR was carried out on a 7500 Real-Time PCR System (Applied Biosystems, Santa Clara, CA, USA) using a SYBR ${ }^{\circledR}$ Green Real-Time PCR Master Mix (Toyobo, Qsaka, Japan) following the manufacturer protocol. Cycling parameters were: $50{ }^{\circ} \mathrm{C}$ for $2 \mathrm{~min}, 95{ }^{\circ} \mathrm{C}$ for 1 min followed by 40 cycles of $95{ }^{\circ} \mathrm{C}$ for $15 \mathrm{~s}, 55^{\circ} \mathrm{C}$ for $15 \mathrm{~s}$, and $72{ }^{\circ} \mathrm{C}$ for $1 \mathrm{~min}$. Dissociation curves were analyzed at the end of each run to determine the purity of product and specificity of amplification.

Experimental design and statistical analysis: A completely randomized design was used for all treatments. All the experiments were repeated three times for each treatment. Data were statistically analyzed using analysis of variance (ANOVA). The mean separations were carried out using Duncan's multiple range tests and significance was determined at $0.5 \%$ level.

MeJA was increased up to 500 and $1000 \mu \mathrm{mol} \mathrm{dm}{ }^{-3}$, the polysaccharide production decreased. The polysaccharide production increased with the culture time. In addition, the low concentrations of MeJA promoted seedling growth and high concentrations of MeJA inhibited their growth (Fig. 2).

The activities of SPS and SS in D. officinale were significantly enhanced after the seedlings were treated with 50, 100, and $200 \mu \mathrm{M}$ MeJA. But the SPS activity decreased after treatment with 500 and $1000 \mu \mathrm{M}$ MeJA. The SS activity decreased after treatment with $1000 \mu \mathrm{M}$ 
MeJA. Thus, the maximum SPS and SS activities were obtained by adding $200 \mu \mathrm{M}$ MeJA (Fig. 3). The results were consistent with polysaccharide content determination. As the polysaccharides affect pharmacological values of Dendrobium, their purification and structural elucidation are still needed. MeJa increased the polysaccharide content of Dendrobium, but further research is needed to find its specific effects on polysaccharides components. MeJA regulated SPD and SS activities but as concern other enzymes involved in sugar metabolism (Zhang et al. 2003) further studies are needed.

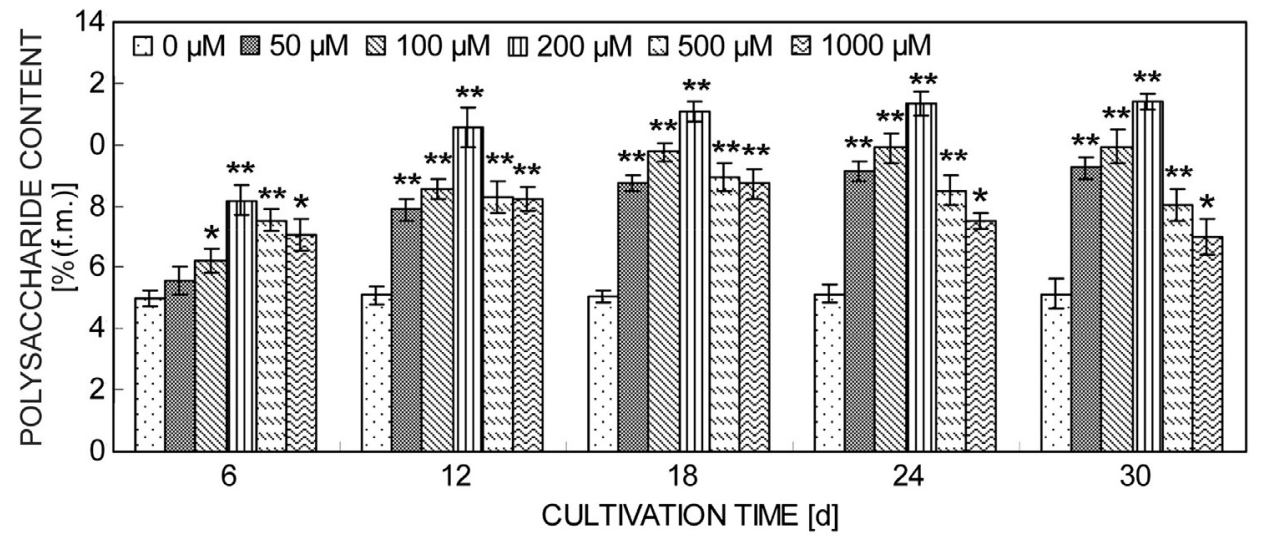

Fig. 1. Effect of different concentrations of methyl jasmonate on polysaccharide content in Dendrobium officinale seeedlings. Means \pm SEs of three independent experiments. ${ }^{*},{ }^{*}$ - indicate significant differences at $P<0.05$ and $P<0.01$, respectively, according to Duncan's multiple range test.
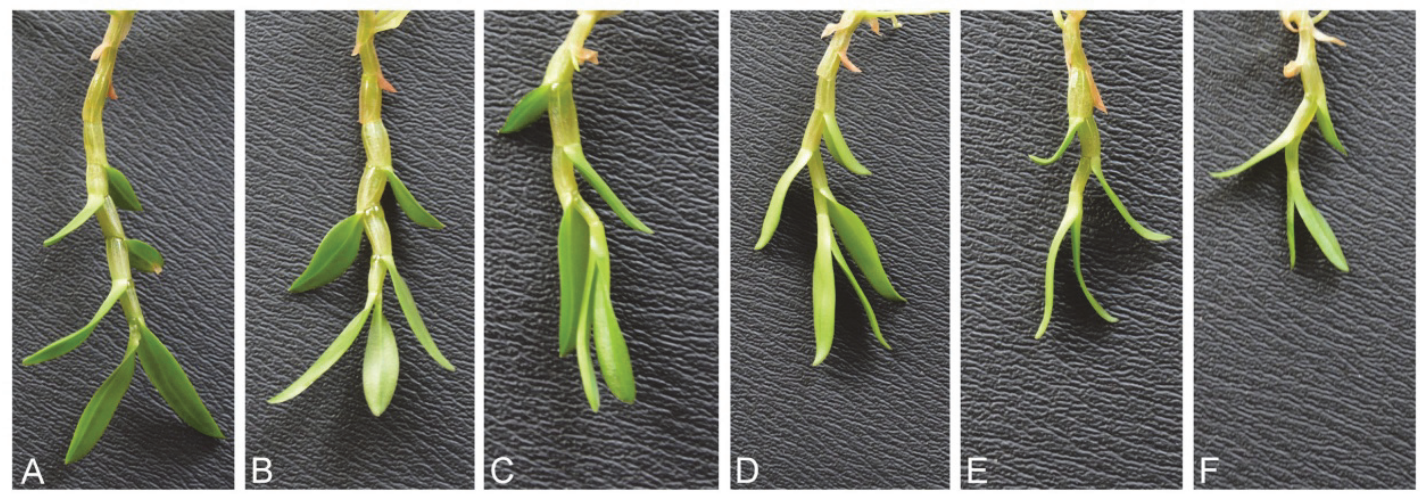

Fig. 2. Effect of methyl jasmonate on seedlings of $D$. officinale: $A$ - control, $B-50 \mu \mathrm{M}, C-100 \mu \mathrm{M}, D-200 \mu \mathrm{M} . E-500 \mu \mathrm{M}$, and $F-1000 \mu \mathrm{M}$ MeJA.

HPLC was often employed to determine the content of polysaccharides. The derivatization and chromatographic conditions were optimized to obtain chromatograms with a good resolution of adjacent peaks within a short analysis time. The monosaccharide composition of the polysaccharides is mainly mannose and glucose (Xia et al. 2012). The concentration of derivatizing reagent PMP should be adequate enough to guarantee the sufficient reaction of the analytes. In this study, the introduction of PMP into the molecules of monosaccharides increased the hydrophobicity of the analytes and made them elute at increased retention times. Thus, the interaction between the analytes and the column was greatly increased. A large excess of PMP was used for derivatization reaction, therefore, removal of residuary reagent by chloroform extraction before HPLC analysis was necessary. The effects of derivatization reaction time on peak area of derivative products in HPLC were essential. PMP derivatization reaction time was usually selected to be $100 \mathrm{~min}$ and the peak area of derivative of each sugar exhibited the maximum (Dai et al. 2010). This method was validated to be sensitive, precise and accurate, and has been successfully applied to the quantitative determination of monosaccharide components in polysaccharide samples. The content of monosaccharides was calculated according to the peak area. There was a considerable variation in the yield and ratio of monosaccharides depending upon the MeJA concentration (Fig 4). The content of glucose and mannose significantly increased with increased MeJA concentration up to $200 \mu \mathrm{M}$ and also with the culture time. 


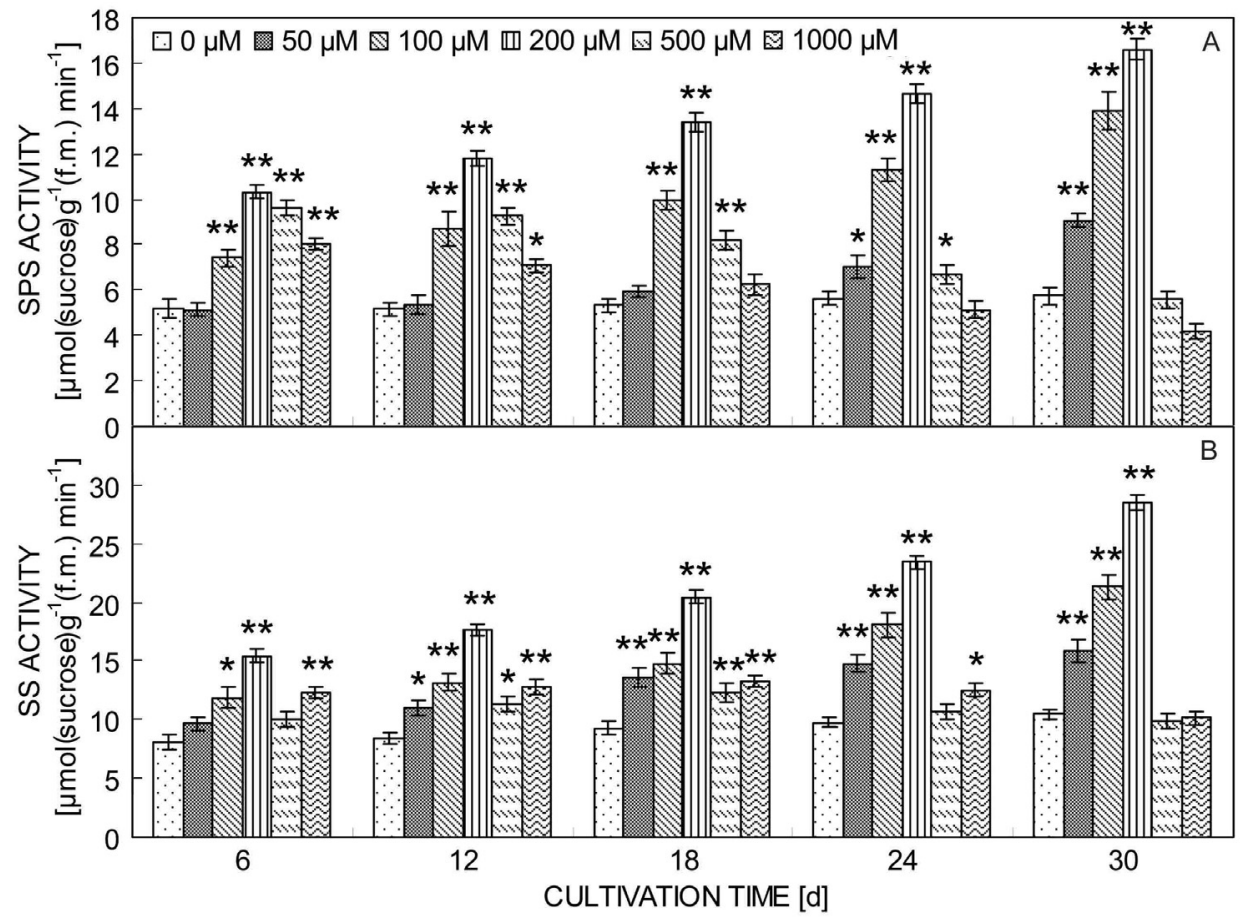

Fig. 3. Effect of methyl jasmonate on SPS $(A)$ and SS $(B)$ activities in D. officinale seedlings. Means \pm SEs of three independent experiments. ${ }^{* * *}$ - indicate significant differences at $P<0.05$ and $P<0.01$, respectively, according to Duncan's multiple range test.

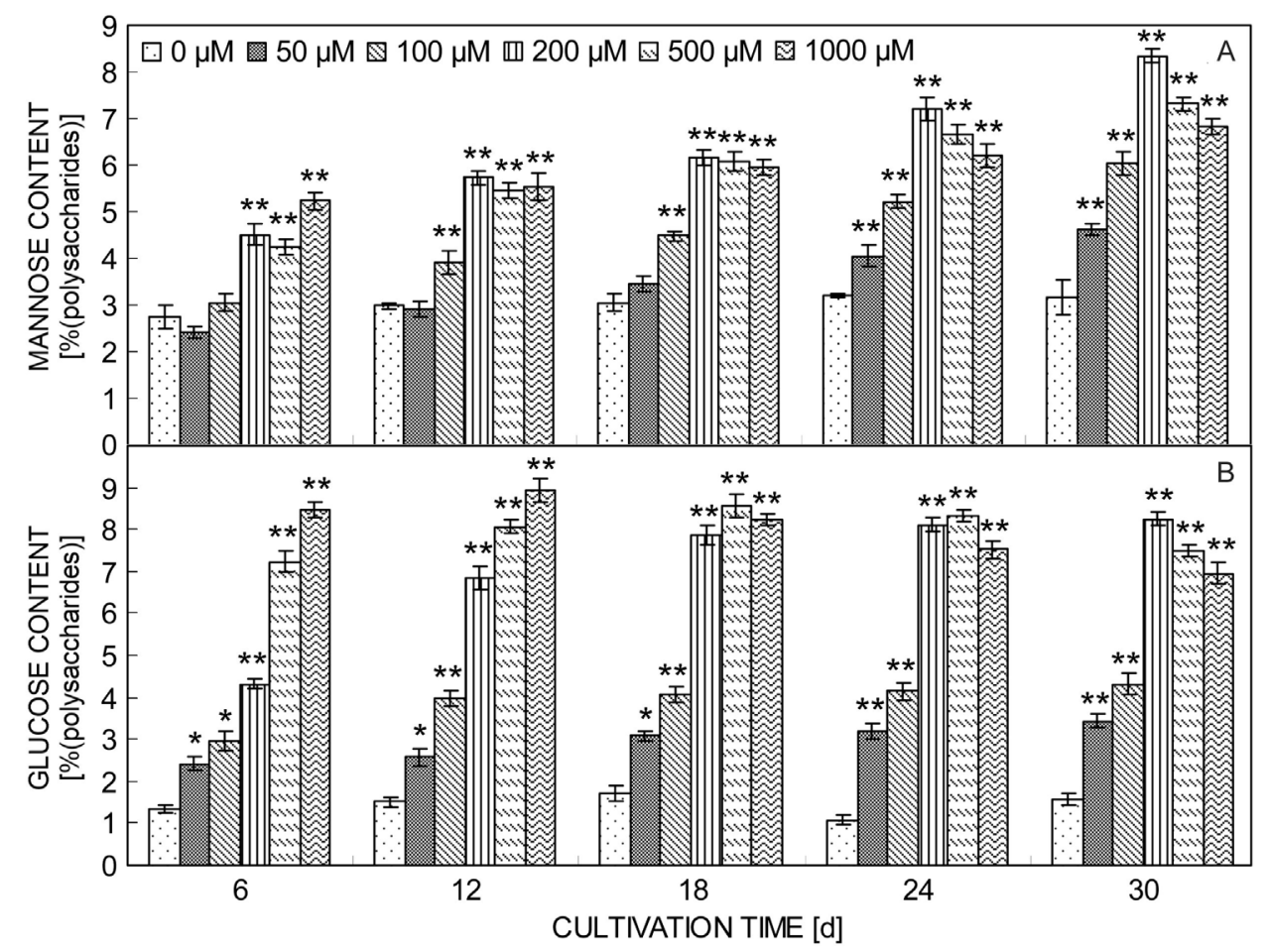

Fig. 4. Effect of different concentrations of methyl jasmonate on mannose $(A)$ and glucose $(B)$ content in $D$. officinale polysaccharides determined by HPLC. Means \pm SEs of three independent experiments. ${ }^{*}, * *$ - indicate significant differences at $P<0.05$ and $P<0.01$, respectively, according to Duncan's multiple range test.

The expression of sucrose metabolism related genes, such as $S P S$ and $S S$, significantly increased after the addition of MeJA (Fig. 5). This suggests that MeJA enhanced sucrose accumulation in D. officinale was 
caused by regulating the expressions of sucrose biosynthetic genes. Nevertheless, when the concentration

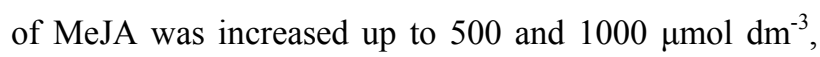
the expression of sucrose synthetic genes was inhibited.

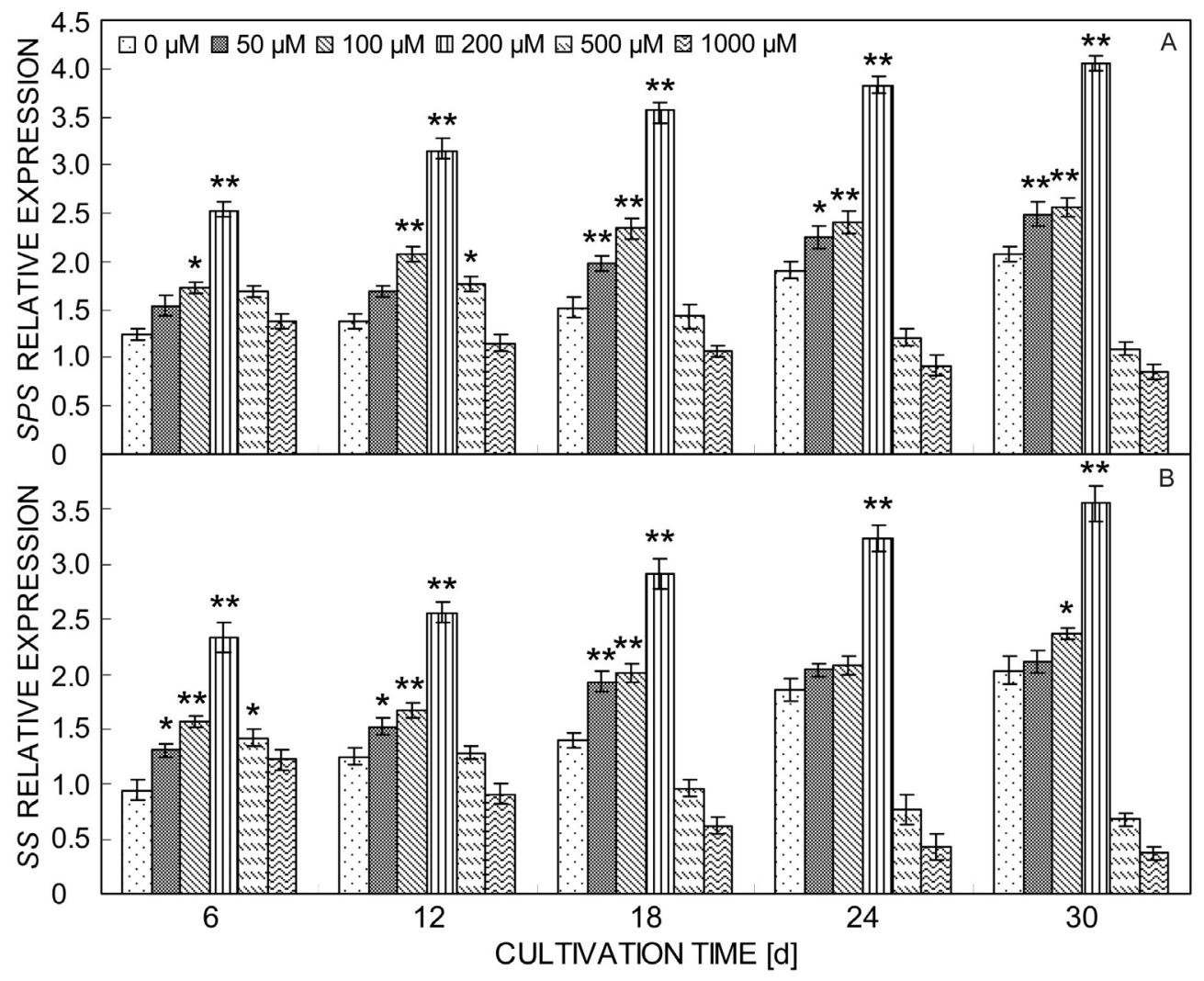

Fig. 5. Effect of methyl jasmonate on genes expression of SPS $(A)$ and $S S(B)$ in $D$. officinale. Means \pm SEs of three independent experiments. $*^{* *}$ - indicate significant differences at $P<0.05$ and $P<0.01$, respectively, according to Duncan's multiple range test.

The polysaccharides in this species were composed mainly from mannose, glucose, galactose, fructose, and xylose. These monosaccharides were produced by sucrose hydrolysis. Thus, sucrose content was directly correlated with polysaccharide content. We found that MeJA influenced the content of polysaccharides, the activities of SPS and SS and SPS and SS genes expression. To further understand the molecular mechanisms for the polysaccharide syntheses, the promoter regions and tissue-specific expressions of SPS and $S S$ will be analysed in the future. In addition, there is evidence that more than one $S P S$ gene and $S S$ gene family exist in flowering plants (Okamura et al. 2011, An et al. 2014). So the number and expression profiles of SPS gene and $S S$ gene in $D$. officinale will be analyzed in the future. These studies should provide information for a better understanding of polysaccharide synthesis mechanisms.

\section{References}

An, X.M., Chen, Z., Wang, J.C., Ye, M.X., Ji, L.X., Wang, J., Liao, W.H., Ma, H.D.: Identification and characterization of the Populus sucrose synthase gene family. - Gene 539: 5867, 2014

Browse, J.: Jasmonate passes muster: a receptor and targets for the defense hormone. - Annu. Rev. Plant. Biol. 60: 183-205, 2009.

Browse, J., Howe, G.A.: New weapons and a rapid response against insect attack. - Plant Physiol. 146: 832-838, 2008.

Dai, J., Wu, Y., Chen, S.W., Zhu, S., Yin, H.P., Wang, M., Tang, J.: Sugar compositional determination of polysaccharides from Dunaliella salina by modified RP-
HPLC method of precolumn derivatization with 1-phenyl-3methyl-5-pyrazolone. - Carbohyd. Polymer. 82: 629-635, 2010.

Dubois, M., Gilles, K.A., Hamilton, J.J., Rebers, P.A., Smith, F.: Colorimetric method for the determination of sugars and related substances. - Anal. Chem. 28: 350-356, 1956.

Goubet F., Jackson P., Deery M., Dupree P.: Polysaccharide analysis using carbohydrate gel electrophoresis: a method to study plant cell wall polysaccharides and polysaccharide hydrolases. - Anal. Biochem. 300: 53-68, 2002.

Hubbard, N.L., Pharr, D.M., Huber, S.C.: Sucrose-phosphate synthase and acid invertase as determinants of sucrose 
concentration in developing muskmelon (Cucumis melo L.) fruits. - Plant Physiol. 91: 1527-1534, 1989.

Jung, C., Lyou, S.H., Yeu, S., Kim, M.A., Rhee, S., Kim, M.: Microarray-based screening of jasmonate-responsive genes in Arabidopsis thaliana. - Plant Cell Rep. 26: 1053-1063, 2007.

Lingle, S.E.: Sugar metabolism during growth and development in sugarcane internodes. - Crop Sci. 39: 480-486, 1999.

Liu, W.Q., Wang, B.C., Duan, C.R., Li, B.: A method for isolating functional RNA from callus of Dendrobium candidum contented rich polysaccharides. - Colloids Surf. B Biointerfaces 42: 259-262, 2005.

Lowell, C.A., Tomlinson, P.T., Koch, K.E.: Sucrosemetabolizing enzymes in transport tissue and adjacent sink structures in developing citrus fruit. - Plant Physiol. 90: 1394-1402, 1989.

Okamura, M., Aoki, N., Hirose, T., Yonekura, M., Ohto, C., Ohsugi, R.: Tissue specificity and diurnal change in gene expression of the sucrose phosphate synthase gene family in rice. - Plant Sci. 181: 159-166, 2011.

Okudera, Y., Ito, M.: Production of agarwood fragrant constituents in Aquilaria calli and suspension cultures. Plant Biotechnol. 26: 307-315, 2009.

Pauwels, L., Morreel, K., De Witte, E., Lammertyn, F., VanMontagu, M., Boerjan, W.: Mapping methyl jasmonatemediated transcriptional reprogramming of metabolism and cell cycle progression in cultured Arabidopsis cells. - Proc. nat. Acad. Sci. USA 105: 1380-1385, 2008.

Reymond, P., Bodenhausen, N., Van Poecke, R.M.P., Krishnamurthy, V., Dicke, M., Farmer, E.E.: A conserved transcript pattern in response to a specialist and a generalist herbivore. - Plant Cell 16: 3132-3147, 2004.

Salvucci, M.E., Drake, R.R., Haley, B.E.: Purification and photoaffinity labeling of sucrose phosphate synthase from spinach leaves. - Arch. Biochem. Biophys. 2: 212-218, 1990.
Sasaki-Sekimoto, Y., Taki, N., Obayashi, T., Aono, M., Matsumoto, F., Sakurai, N.: Coordinated activation of metabolic pathways for antioxidants and defence compounds by jasmonates and their roles in stress tolerance in Arabidopsis. - Plant J. 44: 653-668, 2005.

Schenk, P.M., Kazan, K., Wilson, I., Anderson, J.P., Richmond, T., Somerville, S.C.: Coordinated plant defense responses in Arabidopsis revealed by microarray analysis. - Proc. nat. Acad. Sci. USA 97: 11655-11660, 2000.

Vaughn, M.W., Harrington, G.N., Bush, D.R.: Sucrosemediated transcriptional regulation of sucrose symporter activity in the phloem. - Proc. nat. Acad. Sci. USA 99: 10876-10880, 2002.

Vázquez-Flota, F., Hernández-Domínguez, E., Miranda-Ham, M.de L., Monforte-González, M.: A differential response to chemical elicitors in Catharanthus roseus in vitro cultures. Biotechnol. Lett. 31:591-595, 2009.

Xia, L.J., Liu, X.F., Guo, H.Y., Zhang, H., Zhu, J., Ren, F.Z.: Partial characterization and immunomodulatory activity of polysaccharides from the stem of Dendrobium officinale (Tiepishihu) in vitro. - J. Funct. Foods 1: 294-301, 2012.

Yuan, Z.Q., Cong, G.Y., Zhang, J.Y.: Effects of exogenous salicylic acid on polysaccharides production of Dendrobium officinale. - S. Afr. J. Bot. 95: 78-84, 2014.

Zhang, Y., Chen, K.S., Zhang, S.L., Ferguson, I.B.: The role of salicylic acid in postharvest ripening of kiwifruit. Postharvest Biol. Technol. 28: 67-74, 2003.

Zhang, L., Fan, M.C., Feng, X.W., Liu, X.Y., Wei, R.: Study on the extraction of Dendrobium candidum polysaccharides and dendrobine by cellulose. - Chem. Res. Appl. 3: 356359, 2011.

Zhao, Y., Son, Y.O., Kim, S.S., Jang, Y.S., Lee, J.C.: Antioxidant and anti-hyperglycemic activity of polysaccharide isolated from Dendrobium chrysotoxum Lindl. - J. Biochem. mol. Biol. 40: 670-677, 2007 